\title{
Teacher and Parent Perspectives on Looping
}

By: Archana V. Hegde, Deborah J. Cassidy

Hegde, A., \& Cassidy, D. J. (2004). Teachers' and parents' perspectives on looping. Early Childhood Education Journal, 32(2), 133-138. doi: 10.1007/s10643-004-1080-x

The final publication is available at Springer via http://dx.doi.org/10.1007/s10643-004$\underline{1080-x}$

\author{
***Reprinted with permission. No further reproduction is authorized without written \\ permission from Springer. This version of the document is not the version of record. \\ Figures and/or pictures may be missing from this format of the document. $* * *$
}

\begin{abstract}
:
This manuscript describes the implementation of looping or continuity of care in a high-quality child care facility. Through interviews with parents and teachers, themes were identified including the advantages (stability and continuity of care, ease in transition, anticipating children's needs, parent friendships and networking) and challenges (caregivers' age group preference and skills, planning classroom activities, strained parent teacher relationship, transition from looping and philosophies, no opportunity to experience new things). The reality of implementing the practice of continuity of care and recommendation for implementation are discussed.
\end{abstract}

Keywords: early childhood education | child care | looping | teacher parent perspectives

Article:

INTRODUCTION

"It was a matter of opportunity, there was a vacancy for an infant teacher." Elizabeth thought it would be fun to be an infant teacher and continue with the group until the children transitioned to kindergarten. This compelling opportunity led her child care center implement "looping." Continuity of care or looping is "the practice of keeping the same caregivers with a group of preschool children, infants and toddlers for two to three years"' (Miller, 1995, p. 75). Looping or persistence grouping is more often the term used to refer to continuity of care that occurs from kindergarten to middle or high school. However, these differing terminologies have been used to denote the same underlying notion, that is, the same teacher educating and caring for a group of children for at least two years. This practice exemplifies the importance of bonding, attachment and security between a child and a teacher and increased communication and trust between parents and teachers. Within the field of early childhood care and education it is emphasized that "changes in caregivers during infancy and toddlerhood must be avoided and the number of infants and toddlers with whom one caregiver can form appropriate relationships is necessarily limited’' (Zigler \& Lang, 1991, p. 85).

There is an increasing interest in the concept of looping, as experts in the field see inherent advantages to looping, not only for the child, but also for the benefit of teachers and parents. Proponents of looping assert that looping benefits children in many ways, which include 
overcoming emotional problems (defiance, shyness and sensitivity) (Chirichello \& Chirichello, 2001), alleviation of anxiety about the new year (Hanson, 1995) and more self-confidence (Groves, 2000). For infants and toddlers, a secure attachment between the caregiver and themselves may relate to other areas of development, areas such as, socioemotional development, cognitive development and language development. However, these relationships have not yet been field tested (Cryer, Hurwitz, \& Wolery, 2001).

\section{Reality of Looping}

A study conducted by Cryer, Hurwitz, and Wolery (2001) reveals that across the United States the practice of looping with infants and toddlers is still rarely practiced. Surprisingly, there was no difference between National Association for the Education of Young Children (NAEYC) accredited and non-accredited programs in terms of the number of early childhood programs that practiced looping. Looping is consistent with the NAEYC philosophy that has been stated in the accreditation criteria, that is, " . . .every attempt is made to have continuity of adults who work with children, particularly infants and toddlers.” (NAEYC, 1991, p. 40). Indeed in many other countries, including many European and Japanese schools, the phenomenon of looping is fairly common (Groves, 2000).

Looping has many challenges. Teachers leave the early childhood field at a very high rate each year. Approximately $30 \%$ of the teachers are estimated to leave the early childhood teaching profession annually (U.S. Department of Education, 1997) and the effect on continuity of care cannot be underestimated. High rates of teacher turnover during the infant/toddler years in many of the child care centers, at least in part due to low wages and perceived lack of respect for the profession, has made it nearly impossible to practice looping.

The literature has little or no evidence regarding how continuity of care is implemented in the few child care centers where it has been attempted. Attempts have been made to assess and understand the extent to which different child care programs use looping and understand what factors foster or hinder this process. However, no documentation on continuity of care with young children has delineated the teachers' and parents' perspectives on looping although some literature on looping practiced with elementary children suggests that parents have conflicting views on looping (Nichols \& Nichols, 2002). The current project documents both teachers' and parents' perspectives on looping.

\section{LOOPING IN A HIGH-QUALITY CHILD CARE FACILITY}

At a university affiliated child care center in the southeast, the practice of looping has been implemented. The concept was proposed to the center director by one of the teachers who worked in a preschool classroom. In the interest of the program and because of the lack of documentation of this phenomenon, the teacher proposed that the process be documented through teacher and parent interviews.

\section{Teacher Interviews}


Two teachers, one with a BS degree in psychology and the other with a BS in early childhood education who were the co-teachers in the infant classroom when looping began were interviewed. These teachers have completed their second year of looping. A total of six children were transitioned from the infant to the toddler classroom (which is housed in a separate building) with the same teachers, and two more children were newly recruited. Thus, the toddler group was comprised of eight toddlers. Interviews were scheduled with parents and teachers in order to determine their perspectives on looping. Interviews were conducted at times that were convenient to both parents and teachers. All the interviews were conducted in the child care center in a private room so that parents and teachers were assured of confidentiality. The questions asked were open ended and the length of the interview varied from 1 to 2 hours for the teachers while for parents it was limited to thirty minutes.

\section{Teacher and Parent Interviews}

Overall, these teachers felt that being with the children over time as their primary caregivers was essentially advantageous and beneficial to these young children. The continuity allowed these children to feel more secure and stable. Further, in many ways this led to building a more secure and a trustworthy relationship between the teacher and the children.

Theme 1: Stability and continuity. The first theme that teachers identified was "stability and continuity for children.’' One teacher explained that,

For children this continuity of care and being a primary caregiver has provided them with extra stability. Transition from the infant room to the toddler room has been less difficult for them. This ease in transition has been a result of a secure attachment of the children with us.

Parents held similar opinions, although they were more likely to identify it as "familiarity and consistency."' They believed that looping helped teachers and children to build a very strong relationship with one another. In addition, parents believed that looping could benefit children and the group dynamics in many ways. The possibility of developing long lasting friendships between children was also strongly expressed. One parent said,

Looping is a very good idea and it is very essential for the development of the child. Consistency that comes with looping is essentially very advantageous to the child. The caregiver has a good understanding of the child, knows the child's temperament, wants, strengths and weakness.

Another parent expressed similar sentiments and said, "Consistency is what I like the most about looping. Knowing Rose, this issue becomes all the more important, she doesn't like change, you see." Whereas, another parent thought,

Consistency and a stable environment is what a child can get the most, if he is with the same teacher throughout. The child is very comfortable, familiar and used to, not only to the teacher, but also to the children. 
Furthermore, "Having the same teacher over the years is very beneficial for the child, as that gives them a sense of security." Also, "The same teacher's consistent use of discipline and a particular type of disciplining is really helpful," said another parent. According to one parent, "Knowing and having this little family of friends was fun. At this stage they are like siblings and there is that little daycare family." In a similar vein, another parent thought, "Being with same kids can also help the child because then he can form very strong long-term relations."

Theme 2: Ease in transition. In addition to the themes mentioned above, many parents reportedly mentioned "ease in transition" in their conversations as one of the benefits of looping for their children, although the children remained with the same teacher they moved to a new classroom in a new building, often a traumatic change for young children. In the literature, there is evidence in the literature which supports what parents said. Transitions to new environments and people can be stressful for very young children (Field, Vega-Lahr, \& Jagdish, 1984; Howes \& Hamilton, 1993). Child care centers, where continuity of care is not practiced, use a variety of strategies to make transitions smoother for young children including having parents stay with their child for extended periods of time and gradually having children increase the length of time in the new classroom. Thus, parents' perception of looping as being beneficial and aiding children in their transitions to a new classroom isn't surprising. One parent stated, "My child did not have any problems with any of the transitions. She could move to new places easily and adjust very easily to new surroundings." Another parent said, "It was very easy for Lisa to adjust to this new environment because she had the same teacher and the same children around."'

Yet another parent felt that,

When my child moved in from the infant classroom to the toddler classroom you could see the change. It affected his naps and routines. He used to nap shorter. So, just the change of place was so traumatic to the child. But this looping helped, because even if the place changed, the teachers didn't. A new teacher may not know a lot about this child, whereas these teachers know his body language, wants and needs.

Theme 3: Anticipating children's needs. Teachers' felt that caring for children seemed to be easier each year. During the several years they knew what children needed, anticipated their wants, and knew how to comfort them. In addition, knowing and bonding with families was considered to be an advantage.

Since I have known the children for several years now, I can very readily anticipate their wants and needs. We knew exactly how to put these children to sleep, feed them and how they would react to strangers. We didn't have to start afresh. We knew the children's histories and we could see how far they have come.

The teachers also described a deeper attachment to both the children and the families. They mentioned having "gift of time" in the infant classroom. They could spend a great deal of time holding, feeding and bonding with the children which enabled a strong attachment develop. Overall, a teacher said, 
I would say we have bonded really well with all the families. They seem to feel comfortable with us and they feel free to ask any questions. However, there has been one family we have had differences with, which has made communication sometimes difficult. However, now in the future if any problem arises, we can handle it as we know the history of that family. The ability to know them and working with their child is very valuable.

This teacher identified one of the concerns raised by many others about looping_ " What if the family and the teacher don't bond with the looping caregiver?’'

Theme 4: Parent friendships and networking. Parents believed that knowing the same set of parents for two years now, a result of looping, helped them form strong friendships and networking opportunities. The other families were used by many parents as resources regarding child care information, child rearing, and other concerns regarding their children. One parent stated,

Knowing other parents of the children is great, there is some amount of a comfort zone that is developed, because we have known each other for a long time now. We can discuss issues of parenting, like how do you handle such and such situation and all that. It is a great feeling indeed.

Another said,

The other advantage of looping is getting to know other parents over time. As a working mom like me it is especially very beneficial as I don't have time like other mothers to have a play date for my daughter usually. But because we are very comfortable with the other parents we make it a point to meet each other and have our children get together and have fun. It's also good to know the parents of the other children. We have play dates organized for them, we also went for a training in the month of March together. We also learn about their philosophies of teaching, disciplining and nurturing and so on from each other. Thus, looping is not only helping our child but it is also helping us a lot as parents.

Two other parents echoed these statements. One parent went so far as to describe the familyfamily relationship as a "strong family network."

\section{The Challenges to Looping}

Teachers and parents were also asked to discuss their challenges and concerns regarding looping. Miller (1995) has suggested that caregivers' preference and strength for working with a certain age group could make looping unsuccessful or impossible in certain child care centers. Also, because more children must be added to the group as the group moved from infancy through preschool years, it was anticipated that there would be some challenges associated with the addition of these children. For the parents, this question forced them to think beyond their experiences of looping with these specific teachers since most of the parents had very positive feelings associated with looping. 
Theme 4: Caregivers' age group preferences and skills. One of the teachers has now realized that being with the same children until they transition to kindergarten as an impossible task for her. Her preference for working with very young children and feeling she is skilled with that particular age group may mean that she will return to an infant group and not complete the loop through age five after this year-the toddler year. She stated,

I strictly prefer working with infants. I just like working with that age group. Younger the better, I enjoy them growing and watching them with their families. It's simply fascinating. Yes, I think I am good with infants. I do love these children, but they are growing and they are going to be two. There are lots of new issues that crop up and one has to take care of all those, I don't prefer that. It's more difficult to be with this age group for me. It's not the children but the age that bothers me.

However, the other teacher, although she considers herself more of a " $p r e s c h o o l ~ t e a c h e r$ ' is committed to the idea of looping. She said,

I always wanted to be a preschool teacher. But at the same time I wanted to try out this new system of looping. Initially, I did find it difficult to be in the infant room, but gradually I got used to it. Nevertheless, if one knows what he or she is good at, then definitely it makes sense that you may want to be with that particular group.

However, addition of the new children to the existing group seemed to be a less of a challenge to both the teachers and the children. One teacher stated,

Until now the old children have been very accepting of the new children. They are more curious about the new children than jealous. I guess, since they know us now, they are emotionally and socially equipped to deal with this fact. Rather, new children have found it difficult to adjust, but that again is more of a personality issue than anything else, for example, we have two new children, one child is very sociable and within no time got acquainted to the other children and mixed freely with them. On the contrary, the other child does not socialize much and always needs us to be close to her.

Theme 5: Planning classroom activities. Another concern mentioned as an issue of looping is the challenge of the teacher needing to learn how to plan activities for a new age group (Trejos, 2001). However these teachers who use emergent curriculum and observational planning did not find planning to be a challenge.

For us, curriculum planning is not very challenging, because of the philosophy that we follow. We observe children and plan according to the needs of the children. So at any or every level it is individualized. So if a new child comes in we assess his/her needs and thus plan a curriculum. There are plenty of opportunities to plan activities for a child individually, too, in a group.

Theme 6: Separation after many years or later transitions. As stated previously, though parents viewed looping benefits to outweigh any of its drawbacks, a few concerns were voiced. Most of the parents believed that later separations and transition to kindergarten might become difficult 
for these children. The word transition encompassed a wide range of concerns. The transition from familiar to unknown teachers, familiar environment to a different environment and transition to a different philosophy altogether could become difficult for these children. In addition, not having an opportunity to know a different set of individuals with different strengths and capacities was perceived as a potential disadvantage of looping by a few parents.

As one parent stated, "Well I see only one disadvantage to looping and that is separation anxiety. I wonder what the child will undergo and feel when they have to leave their primary caregiver. I am sure it's going to be difficult." Another said, "For the kids it may be difficult later as they may get very attached to their friends and so when they have to leave they might find it very difficult to do that."'

Theme 7: Strained parent teacher relationship. Another disadvantage mentioned by parents was similar to that mentioned by teachers: What if the teacher, children and the parent don't connect? As one parent said,

The only potential disadvantage that I can envision is that of not having a good relationship with the caregiver and getting stuck with that caregiver because he/she is looping with your child. That may complicate things further and the parent may want to move the child from that child care center.

Theme 8: Transition from looping and philosophies. Yet another concern mentioned by parents seems to have less to do with looping and more to do with the change in philosophy from this present preschool to kindergarten. That is, things will be done differently in the public school setting. One parent said, "I think having the same teacher and same children around may work as a disadvantage, when the child goes to kindergarten or elementary school. Then she will not get this type of opportunity." Another stated,

I am concerned about the transition that the child will have to do when she is going to kindergarten. Not all the schools follow the principles and philosophies of this child care center. It's going to be a lot different for the child. She is going to get used to this way of life and then all of a sudden has to get adjusted to a total new philosophy. That bothers me.

Theme 9: No opportunity to experience new things. Other parents felt looping could be a problem because then children won't get an opportunity to experience new things. One parent said, " One disadvantage is not experiencing different caregivers or teachers. In reality, one does has to experience different types of teachers and individuals in life. Everybody has a different type of personality and one has to adapt to it." Another thought that, "Having a new teacher may be helpful, because he may get some benefit from this new teacher that he would not have gotten if he was with the same teacher every time such as, learning a foreign language."

\section{CONCLUSION}

It seems clear from the parent and teacher interviews that both parents and teachers currently feel very positive about "looping" or "continuity of care" in the child care facility. However, they 
also realize that many challenges may be ahead for their children who have participated in this process. One advantage for this group of children that may alleviate some of the concerns expressed by parents and teachers is that there are teaching teams in each classroom. That is, two teachers with 4-year degrees in each classroom. Therefore, one teacher can continue to loop for the third year with a new co-teacher, while her former co-teacher returns to the infant classroom. This strategy will allow children to loop with one teacher while also being exposed to a new teacher. In addition, children may not have to experience a dramatic change in philosophy, at least the looping philosophy, as children move on to public school. A number of local schools now offer the opportunity to loop to their teachers. However, only a few teachers have taken advantage of this opportunity (Groves, 2000). As the looping philosophy is adopted by public schools children may continue to experience continuity of care as they progress through the elementary grades. All the aforementioned advantages of looping portray looping to be an appealing option, both for children and their parents. However, some proponents of looping still believe that "looping"' should be an option or an alternative for the parents (Chirichello \& Chirichello, 2001). No parent should be forced to enter into this long-term relationship. Also, the parents should be given the option to voice the concerns they have regarding this process. Furthermore, it is critical that teachers working with very young children make a conscious attempt to build relationships with these parents. The center director, coordinator or the supervisor of the child care center needs to assist teachers in reflecting on their practices. Ideally, teachers, parents and the center director periodically should sit together and discuss and reflect on how looping is working for their children and themselves and modifications need to be made.

This manuscript has documented the positive experiences of looping for the teachers and children involved in the process in one childcare center. The responses of parents and teachers is encouraging and will hopefully influence other childcare facilities to implement looping. However, this study did not fully explore the teacher and student characteristics that are most advantageous in making looping a successful endeavor. It is critical to determine whether some teachers and some children would benefit more than others and why this might be true. It would be also very beneficial to know how looping affects children's cognitive, social and emotional development. Nonetheless, this information has provided insights regarding a very important aspect of looping, the perspective of the teachers and parents.

\section{REFERENCES}

Chirichello, M., \& Chirichello, C. (2001). A standing ovation for looping: The critics respond. Childhood Education, 78(1), 2-9.

Cryer, D., Hurwitz, S., \& Wolery, M. (2001). Continuity of caregiver for infants and toddlers in center-based child care: Report on a survey of center practices. Early Childhood Research Quarterly, 14(4), 497-514.

Field, T. M., Vega-Lahr, N., \& Jagdish, S. (1984). Separation stress of nursery school infants and toddlers graduating to new classes. Infant Behavior and Development, 7, 277-284.

Groves, S. (2000, June 7). An exploration of ideas, issues and trends in education; Keeping Teacher, Students in the “Loop”. The Los Angeles Times, pp. BB2-BB5. 
Hanson, B. J. (1995). Getting to know you-Multiyear teaching. Educational Leadership, 53, 42-43.

Howes, C., \& Hamilton, C. E. (1993). The changing experience of child care: Changes in teachers and in teacher-child relationships and children's competence with peers. Early Childhood Research Quarterly, 8, 15-32.

Miller, K. (1995). Caring for the little ones. Child Care Information Exchange, 104, 75-76.

National Association for the Education of Young Children (1991). Accreditation Criteria and procedures of the National Academy of Early Childhood Programs. Washington, DC: Author.

Nichols, J. D., \& Nichols, G. W. (2002). The impact of looping classroom environments on parental attitudes. Preventing School Failure, 47(1), 18-26.

Trejos, N. (2001). More schools getting in the loop; Advocates say familiarity breeds security, success as teachers stay with students for two years or longer. The Washington Post, pp. A12A14.

U.S. Department of Education, National Center for Educational Statistics (1997). Characteristics of stayers, movers and teachers: Results from the teacher and follow up survey: 1994-1995. Washington, DC: U.S. Department of Education.

Zigler, E.,\&Lang, M. (1991). Child care choices: Balancing the needs of children, families and society. New York: The Free Press. 